\title{
Implementation of Online Home-Based Learning and Students' Engagement During the COVID-19 Pandemic: A Case Study of Singapore Mathematics Teachers
}

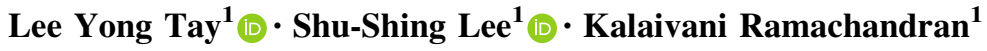

Accepted: 2 April 2021/Published online: 13 April 2021

(C) De La Salle University 2021

\begin{abstract}
The COVID-19 pandemic has forced school closure thus shifting teaching and learning towards full home-based learning (HBL). Technology plays a key role but the considerations to design online learning environments that meaningfully engage students are complex. This exploratory, qualitative study attempted to elicit eight mathematics teachers' considerations and perspectives in designing online home-based learning lessons for the engagement of elementary and secondary students. Data were gathered through interviews. Ground-up thematic analyses were conducted. The following implications are derived-(1) student engagement in online learning context is paramount to their learning, (2) there is no one software application for all the learning activities, (3) teacher professional development is necessary to keep them up-to-date, (4) online social networking platforms may be necessary for students' discussion beyond official online lesson time, and (5) students need to be inculcated with more self-directed skills and habits for learning in online and face-to-face contexts. This study gathers evidence-informed considerations for teachers to design lessons and engage students meaningfully in a unique, online $\mathrm{HBL}$ environment. While this is an exploratory study, future studies can inform this area of work by including more teachers across subjects, grades, schools, and geographical contexts. Studies involving students and parents would also be meaningful.
\end{abstract}

Lee Yong Tay

leeyong.tay@nie.edu.sg

1 Centre for Research in Pedagogy and Practice, National Institute of Education, Nanyang Technological University, 1 Nanyang Walk, Singapore 637616, Singapore
Keywords Home-based learning · ICT in education . Student engagement

\section{Introduction}

The COVID-19 pandemic has put many societies' capacity and capability in handling the situation to the test. Many schools and institutions of higher learning have shifted their teaching and learning activities online due to school closures and lockdowns to reduce virus transmissions, forcing a change from face-to-face mode of schooling to online home-based learning (HBL). Instead of the supportive role, the use of technology has become a core essential for teaching and learning. There are, however, considerations related to issues of using technology for teaching and learning, such as accessibility of hardware and software, screen time, ownership, student engagement and most importantly, pedagogy. In Singapore, despite the short notice and some teething technical and logistical issues, evidences from newspapers (Davie, June 28, 2020; Kurohi, April 14, 2020; Sin, Jun 18, 2020) have shown that the nationwide implementation of online home-based learning was relatively well accepted and implemented.

This study seeks to have evidence-informed understandings by gathering mathematics teachers' considerations about how they designed online home-based lessons and their perspectives of students' engagement during the COVID-19 pandemic lockdown. Although the Singapore education system has reaped the benefits of more than two decades of Information and Communication Technology (ICT) Masterplans since 1997 (Koh \& Lee, 2008), this period of online HBL presented teachers with different challenges and opportunities to explore new modalities in pedagogy. The experimentations and innovations that took 
place during this period are what we believe to be important to document for insights on how teachers designed learning experiences with technology to engage students meaningfully. This paper aims to address this research question, "what are teachers' design of online HBL experiences and how they perceive students' engagement?"

\section{Research Gap-K-12 Student Engagement in an Online Learning Context}

There has been a steady growth in the number of students enrolled in online courses in the United States and other countries, such as, Australia, Canada, and New Zealand. This number has been projected to grow further (Barbour, 2013).

Despite the steady growth and enrolment of online courses, the focus of research about student engagement in online courses has been on institutes of higher learning and not on K-12 students-Patrick and Powell (2009) reported that in a meta-analysis of 51 studies by the U.S. Department of Education in 2009, 44 studies were research on older learners. In addition, the high dropout rates for online courses in institutes of higher learning remain a challenge (Henrie et al., 2015). Borup et al. (2014) highlighted that adolescent online enrolments have increased dramatically despite reports of lower student engagement levels and there are higher student attrition rates when compared with typical face-to-face learning environments (Hawkins \& Barbour, 2010; Rice, 2006). This research gap of continuous increase in online learning and high dropout rates presents an opportunity to study considerations related to student learning in an online context for K-12 students.

Student engagement is paramount for productive learning (Herrington et al., 2003). The key determinant of students' learning experiences relates to professional learning (Mourshed et al., 2010). A research opportunity would be to examine K-12 students' engagement in online homebased learning environments to inform future training and capacity building of teachers and education institutions, especially at the elementary and secondary school levels (i.e., K-12 equivalent). The study of students' engagement in online environments is important because the pandemic presents first hand professional learning opportunities (Borko, 2004) as teachers find ways to meaningfully engage students, leverage technology and teach them content beyond the face-to-face classroom.

\section{A Theoretical Perspective to Study Student Engagement in an Online Context}

A number of studies suggested the importance of taking a sociocultural perspective in looking at students' online engagement (Borup et al., 2014; Burnham \& Walden, 1997; Moore, 1989). More recently, Bond and Bedenlier (2019) also proposed a sociocultural perspective of looking at student learning engagement, taking into considerations of the macro, exo, meso, and micro systems. Inevitably, student learning engagement with technology will be influenced by availability of the national network infrastructure and the accessibility to resources. The micro system, which includes the student, learning environment and technology, teacher, learning activities, peers, and family, is of particular interest and direct relevance to student learning engagement with technology. These above-mentioned factors are elaborated in the following sub-sections to include: (1) definition of student engagement; (2) student engagement in an online learning context; and (3) the different sociocultural elements that shape student online engagement.

\section{Definition of Student Engagement}

Bangert-Drowns and Pyke (2002) define student engagement as the mobilisation of cognitive, affective, and motivational strategies for interpretive transactions while (Kuh, 2003, 2009) sees engagement as the time and energy students devote to educationally sound activities. Students' engagement in a conventional K-12 classroom and school settings are well documented (Fredricks et al., 2004, 2011) as a multifaceted construct. Fredricks et al. (2004) see student engagement comprising three dimensions-behavioural, emotional and cognitive. Behavioural engagement includes forms of positive conduct, such as following of rules, adhering to classroom norms, involvement in learning and academic tasks, and the absence of disruptive behaviours. Emotional engagement refers to the students' affective reactions in the classroom, including interest, boredom, happiness, sadness, and anxiety. Cognitive engagement describes the investment in learning by the students which involves mental efforts and the use of learning strategies to manage learning tasks.

\section{Student Engagement in an Online Learning Context}

Teaching and learning with technology inevitably adds another layer of complexity in understanding student engagement because learning is mediated by both technological hardware and software applications. In studying students' online engagement, Dixson (2015) considers 
these four factors: (a) skills (e.g., keeping up with readings, being organised, and listening and reading carefully); (b) emotion (e.g., putting effort and making lessons meaningful and relevant); (c) participation (e.g., engage in online conversations, interact with other students); and (d) performance (e.g., able to do well in tests and assessments). Martin and Bolliger (2018) further stress the importance of three types of interactions inherent in effective online courses: learner-to-learner interaction, learner-to-content interaction, and learner-to-instructor interaction. Technological hardware and software applications, student factors, and types of interactions are considerations that shape the ways teachers design and implement online learning experiences to engage students meaningfully.

The pandemic situation presents an interesting context and dynamics for studying student engagement because teachers and students had to quickly shift from learning in a face-to-face context to an online environment. Teachers had relatively little time to prepare. There are also uncertainties as to how long learning in the online environment would persist with the possibilities of moving back to the face-to-face environment again. Such a context presents an opportunity to study online student engagement, the sociocultural elements that shaped student online learning engagement and the considerations that teachers made to design online learning experiences for students.

\section{Sociocultural Factors that Shape Student Engagement}

The teacher, learning environment and technology, learning activities, peers and parents are significant sociocultural elements that shape student online learning engagement.

\section{Teacher}

Just like the typical face-to-face classroom learning, students' engagement would be enhanced when student-teacher relationships are strong. There is student engagement when students perceive the teacher to be supportive, effective, and knowledgeable (Baker, 2010; Bond \& Bedenlier, 2019). Everett (2015) reviewed several studies related to student engagement in online learning environments and emphasised the importance of teachers designing purposeful interactions (teacher-student and studentstudent interactions) to facilitate learning. Robinson and Hullinger (2008) suggested that instructors need to purposefully incorporate opportunities for students to learn from one another to create a sense of classroom community, which could potentially enhance students' engagement. Dixson (2010) attempted to examine activities and instructional procedures that might lead to better engagement with students in online learning environment. The findings indicated that there was no particular activity that will automatically facilitate students to be more engaged in online classes. She suggested for online instructors to incorporate multiple and meaningful ways of interacting with students and to design online lessons that encourage and require students to interact among themselves. It seemed that interaction was an important element in online courses (Gray \& DiLoreto, 2016; Martin \& Bolliger, 2018; Martin et al., 2012). Given the short time that teachers had to switch to teaching in the online environment during the pandemic situation, teachers could be presented with different challenges that shape how teachers design for interactions that support student engagement. Thus, there is a research opportunity to study how teachers come together as a community to prepare and implement online learning to support student engagement and the kinds of professional learning that they had to go through.

\section{Learning Environment and Technology}

One of the most fundamental considerations for student engagement and learning with technology is the availability and accessibility to the technology itself (Hew \& Brush, 2007; Tay et al., 2017; Turgut \& Aslan, 2021). Students need to be equipped with the necessary technological hardware (e.g., computers and Internet access) and the technological know-how of operating the technological hardware and navigating the software applications for learning to occur. Given the array of software applications for learning, it would be interesting to understand how teachers choose appropriate applications and its affordances for learning. What would take precedence in teachers' considerations, the technological affordances for learning, students' readiness or using the latest technological tools? The demands on technological hardware would also be high in students' homes as learning and working have shifted to the online environment. Consequently, there could be sharing of devices for learning. For students who do not have access to technology, how would they cope with learning in an online engagement? These questions present opportunities for research to find out how teachers design the online learning experience and student engagement during this period.

\section{Learning Activities}

Several authors highlighted the importance of learnercontent interaction (Martin \& Bolliger, 2018; Moore, 1989). The choice of content (e.g., whether challenging and relevant) and how it is being taught or delivered (e.g., whether active and collaborative forms of learning) impacts students' learning engagement, be it online or in 
face-to-face settings. Patrick and Powell (2009) reported that learning activities and instruction combining online and face-to-face elements had a larger advantage relative to purely face-to-face or purely online instruction. In addition, online learning can be enhanced by giving learners control of their interactions with technological media and prompting of learner reflection. Teachers interacting with students, parents, and colleagues are identified as one of the primary differences between online and face-to-face instruction and as one of the most important aspects of online learning (Weiner, 2003). Teachers are designers of students' learning experiences. It is useful to understand the rationalisations that teachers have in their choice of tools, instructional strategies and learning activities in the online context. How do teachers implement learning activities, as synchronous or asynchronous formats or a combination of formats?

\section{Peers}

Peers are important as they create learning communities where students can interact collaboratively to build peer-topeer relationship, which is very important for learning engagement of students (Everett, 2015; Gray \& DiLoreto, 2016; Moore, 1989; Northey et al., 2015). Peer engagement does not share parents' and teachers' responsibilities for facilitating other students' engagement but they can impact student engagement through collaboration and motivation. Moore (1989) suggested that interaction between learners may be more motivating for adolescent learners than for adults. The opportunity for research is, therefore, to investigate with the various demands and complexities of designing online learning experiences for students in this pandemic situation, how could opportunities for peer-topeer interactions be incorporated? Would content delivery and the monitoring of student learning take precedence over including peer-to-peer interactions in teachers' considerations?

\section{Family}

A number of questions still exist about the effectiveness of online education for K-12 students although it has grown in popularity over the last two decades. Online education started for older students and those in the university. For students in K-12, they must be self-motivated, engaged and participating, and accountable for their own learning. In addition, parents should be available to monitor, mentor, and motivate these students (Archambault \& Larson, 2015; Curtis \& Werth, 2015; Farmer \& West, 2019; Smith et al., 2016). "Parents are one group of stakeholders virtually absent from literature related to K-12 online learning environments. Full-time, online schools often partner with parents to oversee and support students who are completing their education in an online environment. Parents play a significant role in educating students who attend school online, and research has been conducted on their roles" (Curtis \& Werth, 2015, p. 165). Parent engagement can positively influence student engagement by facilitating interaction, organising students' learning environments, and instructing students. Although the roles and responsibilities of parents and teachers are not the same, their influence overlaps. The pandemic presents a unique situation where parents are working and students are learning from homes at the same time. It would be timely to investigate how teachers leverage parents to support students' online learning experiences.

\section{Purpose of Study}

This study contributes by understanding teachers' perspectives and teases out their design, gaps, and possible improvements for teaching and learning mathematics in such an online HBL environment. This paper attempts to document teachers' design and implementations of teaching and learning experiences, their reflections of student engagement, and gaps so that teachers continue to improve on the use of technology for meaningful learning and student engagement after the passing of this looming dark cloud.

\section{Background}

\section{Learning with Technology in Singapore}

Singapore schools are not unfamiliar with online learning as the Singapore Education Ministry has put in place National ICT Masterplans since 1997 as a key strategy to prepare students for the future. Schools have carried out e-learning days in preparation for a national emergency situation and also to enculturate teachers and students for online learning.

To date, schools are well-equipped with the necessary technological infrastructure. Teachers are also trained in how to effectively use technology for their teaching and students' learning. In recent years, the Ministry of Education (MOE) has developed an online platform called the Singapore Student Learning Space (SLS). It contains resources for students so that they can always revisit the lessons to reinforce their learning. It provides curriculumaligned resources and teachers could make use of these resources to design lessons. In addition, the local ministry has led an online network community on ideas to design technology- and online-based lessons on Facebook, known 
as the Singapore Learning Designers' Circle ( https:/www.facebook.com/groups/sglearningdesigners/). This community grew exponentially to more than 15,000 members during the COVID-19 circuit breaker period.

\section{Home-Based Learning in Singapore During Its Circuit Breaker Period}

Full home-based learning in Singapore was declared from 8 April to 4 May 2020 during its Circuit Breaker Period (Kurohi, April 14, 2020). Despite the short notice, there was mass acceptance of online learning by students, teachers, and parents although there were also challenges faced by some of the students and their families (Davie, June 28, 2020). This pandemic had fast-forwarded the use of technology and online learning in many education systems, including that of Singapore. The government of Singapore also announced on 17 June 2020 that all secondary school students will receive a personal laptop or tablet for learning in the coming year -7 years ahead of the original target. "This is one of the ways the government, schools, and the community are working together to keep social mobility alive, and ensure every individual is afforded the opportunity to do well, regardless of his starting point" (Sin, Jun 18, 2020).

\section{Research Design and Method}

Eight mathematics teachers from two elementary and two secondary schools participated in this exploratory, qualitative study. The teachers' profiles are described in Table 1.

Due to the precautionary measures during the period of study (i.e., from late July to August 2020), all teachers were interviewed via Zoom by the three authors. Each teacher interview was approximately $60 \mathrm{~min}$. The semistructured interview involved teachers describing their experiences in designing online HBL, mathematic lessons, how they designed lessons to engage teachers and their

Table 1 Details of mathematics teachers interviewed

\begin{tabular}{lll}
\hline No. & School & Level teaching \\
\hline 1 & Elementary & Grades 4 \& 6 \\
2 & Elementary & Grades $3 \& 5$ \\
3 & Elementary & Grades $5 \& 6$ \\
4 & Elementary & Grade 5 \\
5 & Secondary & Grades 8 \& 9 \\
6 & Secondary & Grade $7 \&$ Grade 10 \\
7 & Secondary & Grade 9 \\
8 & Secondary & Grade 10 \\
\hline
\end{tabular}

perceptions of students' engagement. The semi-structured interview was guided by the questions shown in Appendix with additional questions constructed as the interview evolved based on teachers' responses. All interviews were transcribed for analyses. Ground-up thematic analyses were conducted in phases. Member checking was done throughout the analyses to ensure the validity and reliability of findings.

- Phase 1 -initial coding and familiarisation of data. The researchers read the interview transcripts. Annotations were done together with initial codes to highlight notable considerations that teachers made in designing online HBL experiences and their observations of student engagement.

- Phase 2-analysing codes and identifying themes. The authors discussed their initial codes to understand different interpretations and align any differences. As there were three researchers, any differences were mediated by the third researcher. Initial codes were combined to form an initial set of themes

- Phase 3-reviewing and defining themes. Initial themes were reviewed by regrouping smaller themes to form broader themes or broader themes were divided into subthemes. This process was done iteratively until the researchers came up with a thematic map that adequately described findings.

\section{Findings}

The final thematic map describes findings as two main themes and 4 sub-themes (see Fig. 1). Theme 1 unpacks teachers' considerations for HBL relating to their: (a) design preparations and implementations and (b) professional learning as a community. Theme 2 illustrates students' factors for HBL in the form of teachers' descriptions of: (a) students' HBL engagement and (b) readiness.

\section{Theme One: Teachers' Considerations for HBL}

Theme one describes how teachers prepared and implemented HBL lessons by consolidating technological tools and ideas for implementing lessons in synchronous and asynchronous formats.

\section{Teachers' HBL Preparation and Implementations}

Teachers Consolidating Technology and Lesson Ideas Teachers prepared for the possibility of school closure and online HBL by working as a community to consolidate and share useful software applications so teaching and learning could continue. "We have our level 
Fig. 1 Thematic map

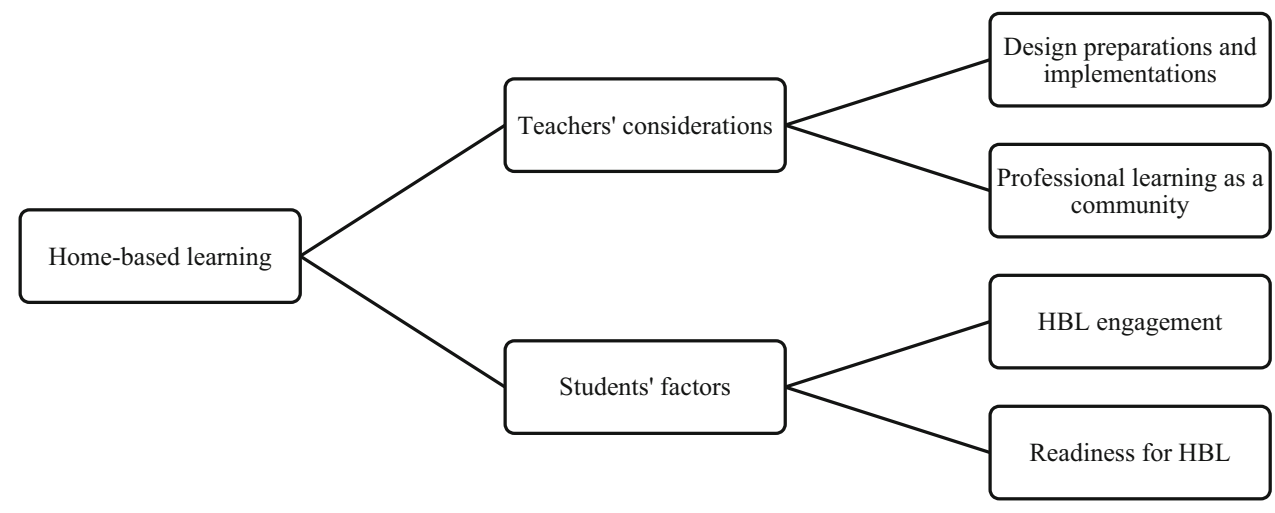

meetings.... we discuss about the things that we want to do with our students and then that is how we share and cross pollinate the ideas...". The school timetable was re-organised to manage students' screen time. Teachers used the ministry's SLS platform and supplemented it with other tools (e.g., Google applications) to implement online HBL. Technology familiarisation sessions were conducted for teachers who needed instructions on how to use online applications for HBL. Teachers also shared lesson ideas and resources across schools through an existing community, Learning Designers Circle Facebook page, which was set up by Educational Technology Division (ETD) of the Ministry of Education (Singapore). "There is SGLDC [Singapore Learning Designers Circle], it is a Facebook group ... teachers will share their lesson ideas, their considerations on that Facebook page. So, I will use the materials that I found there and share with my teachers." In addition, teachers also reviewed their scheme of work and decided to teach topics that required students to acquire less conceptual understanding during HBL. "I think it depends on topics... because certain topics, say construction, I don't think I can actually put that into a home-based learning. I really need to tell them physically how to do certain things."

Teachers Implementing Lessons in Synchronous and Asynchronous Formats Online HBL was implemented in synchronous and asynchronous formats to emphasise subject content delivery and monitor students' learning. "It is a mix of synchronous and asynchronous teaching. So, depending on the level, depending on the type of student profile of the class...". Teachers could implement more variations of $\mathrm{HBL}$ for higher grade students by toggling between formats in contrast with elementary students who needed more teachers' support. Typically, lessons included three segments (1) reviewing students' mistakes in the assigned homework; (2) teaching lesson content; and (3) clarifying understandings through question and answer. Teachers acknowledged that they needed more time to design teaching resources, so they leverage existing materials from SLS and adapted it accordingly. Teachers also shared their teaching resources with communities within and beyond schools to support each other.

Lessons in synchronous formats used video conferencing software application (e.g., Zoom) to mimic classroom practices and implemented all three segments as "live" sessions. "There was a lot of promotion on use of video conferencing in Google Meet and zoom ... a lot of what was being delivered was the same thing, frontal teaching, classroom teaching”. Synchronous lessons lasted between 35 and 40 min. Each segment was no longer than 15 min because teachers were mindful of students' attention span. "For the HBL to be effective, maybe the lesson cannot be one hour... because one hour is actually quite strenuous on the eyes...it is only like about 35-40 min." Synchronous lessons were also digitally recorded and uploaded to SLS or Google Classroom so students, particularly absentees, could revisit lessons. Teachers found it challenging to monitor students' engagement and learning online as students could be multitasking. Furthermore, the 'cut and paste' technological affordance meant students could plagiarise answers from online sources. "not every lesson that I do, will be live [synchronous]. So, I will mix it up a little bit. Sometimes it's [asynchronous] just assessing SLS, sometimes it's just doing the timed practice on their own...". Asynchronous lessons implemented the first and third segments described earlier as "live" sessions. The second segment was implemented as an "off-line" experience where students accessed teacher prepared lesson resources in SLS, PowerPoint slides or screencast with the teacher's voice, and teacher curated learning activities from the Internet (e.g., educational websites or digital videos). Teachers monitored students' progress and understanding by using self-marking functions when it was available in software applications, by getting students to take pictures of the written mathematics solutions and submitting it through the relevant software applications or by using the inking function on laptops and tablets to grade students' work and provide feedback. Teachers also taught students to file their online homework for future revisions. 
Constant feedback was exchanged between students and teachers to refine the HBL lessons.

\section{Professional Learning as a Community_Just-in-Time Professional Learning}

Before school closure for HBL, just-in-time professional learning sessions were conducted to update teachers about the latest technological tools. Teachers also attended online tutorials to learn about different software applications to support HBL. " a lot of like online learning platform that were available. So, the ICT head will tell us, oh if you want to learn about how to use Google Classroom, there is this online lesson, tutorial like that..." Occasional trouble shooting was done amongst teachers and technical personnel using emails and mobile phone applications (e.g., WhatsApp) to ensure the HBL run smoothly. "we had some form of professional development.... Then during the $H B L$ period, we were very actively using the WhatsApp level chat, like oh, I have difficulty with this and all, what do I do. So, we are helping each other... Yeah, so that helps a lot." The teaching community supported each other by sharing different ideas and diverse perspectives for teaching and learning with technology.

Teachers acknowledged that HBL required more time and resources. However, it was not necessary for them to have or learn about the latest technology for HBL. "it's not so much of the number of apps to learn to use at this point in time. It's more of like, okay, like how do you enhance the use of zoom. ....., I want to learn how to further leverage on those apps. ... you know, learn more about what other features of these apps, like for example, zoom, you can organise them into different chat groups and then they can discuss about certain problems, then after that they can come back to the main class." It was more important for teachers to have professional learning experiences that focused on understanding and using the affordances of technological tools to design meaningful learning experiences. Teachers welcomed the sharing of resources and teaching ideas within and across schools.

\section{Theme Two: Student' Factors for HBL}

Theme two describes students' engagement and readiness for HBL. The two sub-themes describe teachers' considerations to support students' emotional, behavioural, cognitive and social engagement during $\mathrm{HBL}$ as well as teachers' understandings of how students' readiness for HBL is shaped by accessibility of technology, maturity and age.

\section{Students' HBL Engagement}

Teachers Leverage Novelty Effects and Parents to Support Emotional Engagement Students' emotional engagement were important considerations as teachers designed and enacted HBL experiences. The novelty effects of technology got students excited to start the online HBL experience. Even before the HBL period, when students were brought to the computer laboratory to familiarise with the Zoom software application, they were very excited about it. "It was like shiny new platform; it was like a novelty for them". As the weeks progressed, fatigue set in. "So, I think after a while, it wears off, you see."

Students from graduating classes became insecure over missing schools and their pending examinations. "I think the kids who are sitting for national exams, I think they are also feeling quite worried and insecure, that we didn't have a mid-year exam or some assessments." Teachers tried to allay students' fears by using synchronous online video conferencing to check-in and chit-chat with them and support their emotional well-being. Teachers also worked with parents and guardians to ensure students had emotional support during this period of learning.

Teachers Manage Classroom Discussions and Issues to Support Behaviour Engagement The HBL environment was conducive for learning because students could pay attention without disruptions from classmates. Compared to the classroom environment, "quietness" could be maintained because teachers could mute all or some students in the online environment. Talkative or disruptive students could be managed by technology. One interesting observation was that students who were usually quiet and less participative in face-to-face contexts became proactive in asking questions and participated actively. "I finally hear those quieter ones, when they have questions, they finally start to ask. Because usually in a physical classroom, I think it will be dominated by the vocal ones."

The online environment also brought about behavioural engagement issues, such as students being late, absent, multitasking, and late homework submission. For some students, teachers had to call up students or their parents/guardians to find out reasons for being late or absent. Teachers managed students' behavioural engagement by requesting students to activate their webcam to mark attendance and check their identity. Teachers wanted to ensure students were at their computers all the time and paying attention. Teachers also reflected that students needed more "chasing" to submit their homework in an online environment. 
Teachers Recognise the Importance of Assessment, Feedback, and Guidance for Cognitive Engagement Teachersassociated cognitive engagement with the learning of content knowledge. Teachers were more confident of students' cognitive engagement in the face-to-face setting than the online environment. Teachers observed that students who were usually engaged or self-directed students in the classroom remained equally engaged in the online setting. "students who show up for my live lessons will tend to be the more engaged and the more serious ones.... they are listening and as I'm explaining a certain question, usually from the workbook or textbook, they are there writing down or taking notes".

Teachers recognised that online formative assessments were key in online HBL to gather students' feedback on their understanding and progress. Unlike the physical classroom, where such feedback could be done seamlessly and adapted "on the fly", the online environment required prior planning. Thus, teachers had to adjust their practices. "One of the things, I thought was an issue for home-based learning, was that there's less face time, so harder for us to give feedback. Immediate feedback. So, like doing [face-toface] lessons we can, I can move around, you know... and I can point them their mistakes straight away."

Teachers also reflected that younger or special needs students needed more guidance because online HBL posted different learning challenges and additional demands of handling technology. Even when lesson packages were well-designed, these students needed home support to facilitate cognitive engagement.

Teachers Acknowledge Constraints for Social Engagement Teachers shared that peer-to-peer discussions were less prevalent in online HBL contexts. However, teachers had the inclinations that students engaged in discussions outside of lesson time. "They will, like chat with each other, either by calling each other or by texting each other, outside of the lesson, like in their own time. We learnt that through chatting with them in the morning..." Interactions during online asynchronous lessons were mainly between teacher and students. Teachers felt that the limited studentto-student interactions could be attributed to how teachers kept lessons within 30-40 min.

\section{Students' Readiness for $H B L$}

Students' Readiness is Shaped by Accessibility of Technology Accessibility of technology plays a role in students' readiness for HBL. Some students did not have technological devices or had to share technological devices with siblings to access online HBL. Schools mitigated these issues by loaning computing devices to these students.
Learning with technology is not new to teachers and students, thanks to the consistent efforts by schools and the ministry of education since the first ICT Masterplan in 1997. Prior experiences with virus like SARS, H1N1, and MERS, which threatened to close schools, had also prompted the ministry of education to have periodic learning experiences with schools to prepare teachers and students with the possibility of online HBL. Consequently, teachers and students, are ready for HBL. However, the lengthy 4 weeks of HBL was unprecedented. Teachers reflected that students rose to the challenge because they understood the seriousness of the situation and persevered in learning. This experience forced students to become selfdirected learners, especially for those in the upper elementary (Grades 4-6) and secondary (Grades 7-10) levels. "I think the benefits is that the home-based learning, basically, I think it forces the kids to be independent in their learning. ... I realised, that the success of homebased learning, it's really self-directed and being independent in their learning and being able to do that."

Students' Readiness for HBL is Shaped by Their Maturity and Age Teachers mentioned that students' maturity, in terms of self-directedness, motivation and ICT-savviness, and age, played a role in their engagement of the online HBL experience. "I see a general trend with the younger ones. I think they are not so used to this. This whole homebased learning. I think the older ones actually adapt a lot faster." Younger students, especially those from Grades 1-3, needed more synchronous learning experiences and support from adults at home. Secondary students (Grades 7-10) seemed more self-directed and could manage asynchronous lessons. "Then, for your really, really low progress, your specialised groups, ...video conferencing really helped them." Lower progress and special needs students needed face-to-face experiences with teacher scaffolding and guidance at home for HBL to be productive. "we need to monitor. So, usually, this type of students, we monitor and realise they have an issue, they cannot study at home. They have to call back to school, this is called special need." Special arrangements were made for students with special needs to return to school so teachers could conduct either one-to-one or small group lessons for them.

\section{Discussion and Implications}

The two themes in findings gleaned five recommendations for online HBL experiences (see Table 2). These recommendations are discussed below. 
Table 2 Summary of practical implications

\begin{tabular}{ll}
\hline Theme one: teacher considerations & Theme two: student factors \\
\hline $\begin{array}{l}\text { Teachers need to make deliberate and consistent efforts to monitor } \\
\text { students' engagement and progress }\end{array}$ & $\begin{array}{c}\text { Expand online learning spaces to include social network } \\
\text { platforms for students to continue discussions beyond lesson } \\
\text { time }\end{array}$ \\
- Teachers use a variety of software applications for their lesson delivery & $\begin{array}{c}\text { Inculcate students with skills and habits for learning in online and } \\
\text { face-to-face contexts }\end{array}$ \\
- Teachers need continuous PD to understand how to more effectively use \\
$\begin{array}{l}\text { instructional strategies and technological affordances for meaningful } \\
\text { learning with technology }\end{array}$
\end{tabular}

\section{Implications-Teacher Considerations}

\section{Teachers Need to Make Deliberate and Consistent Efforts to Monitor Students' Engagement and Progress}

Dynamics of online HBL makes monitoring students' progress more complex than face-to-face lessons. The shift in medium of instruction, from face-to-face to online contexts, changes the dynamics of teaching and learning. Another layer of complexity involving mediation by technology is introduced. As suggested by (Chai et al., 2010, 2019; Koehler \& Mishra, 2009) in the TPACK framework, teachers now need to consider the interplay of technology, pedagogy and content in designing online learning experiences. Other factors of consideration include students' skills, emotions, ways of participation, their performance in assessments, and interactions (Dixson, 2015; Martin \& Bolliger, 2018). Thus, the teaching and learning process becomes more complex which aligns with our findings.

The maintenance of students' engagement is key for productive learning. Teachers interviewed were concerned about students' engagement during the HBL experience. Our teachers reflected that they could observe students' cognitive, behavioural, emotional, and social engagement more easily in a face-to-face setting. Fredricks et al. (2004) describe these three aspects of student engagement but did not draw connections. Our findings seem to illuminate some connections between the three aspects of student engagement. While teachers are concerned about students' content understanding, the practical implication drawn from this HBL experiences is that students' behavioural and emotion engagement were important to support cognitive engagement. Teachers need to purposefully design communication opportunities during online HBL experiences to find out students' concerns and needs, and to maintain a two-way communication channel.
Teachers Use a Variety of Software Applications for Their Lesson Delivery

The practical implications gleaned about the combination of tools teachers used to implement online HBL show that teachers used video conferencing software (e.g., Zoom or WebEx) to create their virtual classrooms, a central repository to house relevant digital resources (e.g., SLS), a communication platform for dissemination and exchange of information (e.g., email systems), assessment applications for the monitoring of students' progress and learning, and discussion forums to support students' exchange of ideas and discussions (e.g., Padlet or Google Classroom). Teachers are not looking for the latest software applications. Teachers are concerned about leveraging the technological affordances for meaningful teaching and learning. Our findings align with literature-such as Martin and Bolliger (2018) and Moore (1989) - to stress that teachers need to focus on learner-content interactions and the technological affordances that tools have to support these interactions. Teachers' choice of content, how it is going to be taught to support students' learning engagement shapes the selection of tools rather than using the latest tools. Thus, it important for schools to equip students with the skills on how to use technology for learning, especially for younger students. Students need to knowhow to use technology before they can use technology for learning. While it is useful for schools to think about a standardised suite of tools to support online HBL, the curation of tools needs to consider teachers' readiness, student profiles, and learning goals.

\section{Teachers Need Continuous PD to Keep Up-to-Date with Educational Technology}

Research shows that the most important determinant of students' learning experiences relates to the quality of teaching and professional learning (Mourshed et al., 2010). Teachers' understandings of instructional strategies and affordances of ICT for learning are enriched when 
professional learning involves continued practice through first hand experiences of online learning in different classroom contexts (Borko, 2004). Continuous teacher professional development is necessary to keep our teachers up-to-date with the technological know-how. Professional learning communities provide possible platforms for teachers to engage in effective, continuous professional learning because it embodies substantive features of effective professional learning which focus on continuity and sustenance (Hairon, 2020).

\section{Implications-Student Factors}

Expand Online Learning Spaces to Include Social Network Platforms for Students to Continue Discussion Beyond Lesson Time

Social engagement seems lacking in online HBL because of the limited lesson duration and functions on video conferencing applications that our teachers used. Teachers acknowledged that there were limited student group work and collaboration sessions. However, they did not rule out that students connect through other social networking platforms for school or social purposes. The practice implications, therefore, is for teachers to expand the online spaces for HBL to include social network platforms for students to continue discussions beyond lesson time. In other words, social engagement as defined by Fredricks et al. (2004) may not be confined to official lesson time during HBL. Teachers could intentionally design for students' social engagement before and after lesson time during the HBL experience. This is important because peer-to-peer relationship is critical to support students' learning engagement (Everett, 2015; Gray \& DiLoreto, 2016; Moore, 1989; Northey et al., 2015).

\section{Inculcate Students with Skills and Habits for Learning in Online and Face-to-Face Contexts}

Our findings show that age and maturity play a role in student engagement and in students having a productive HBL experience. Similarly, students with the right learning dispositions benefited from online HBL. This finding reiterates the importance of continuous inculcating of the necessary skills and habits of being a motivated and selfdirected learner so that students can toggle between learning in the online and face-to-face contexts. As highlighted by researchers (Hew \& Brush, 2007; Tay et al., 2017; Turgut \& Aslan, 2021), student engagement and learning is shaped by technological availability and accessibility. Having access to technological hardware is important but what is more fundamental is for students to have the technological know-how to use the hardware and software so that learning can occur.

\section{Limitations}

This study is limited by the small sample size of eight mathematics teachers. This is an exploratory, qualitative study. The intent is not to make generalisations but to provide initial understandings of how online HBL was conducted during the pandemic to inform future, more indepth studies involving more teachers and subjects. Another limitation is that findings only included teachers' perspectives. It would be meaningful to include students' and parents' voices to have a holistic understanding of student engagement and challenges during the online HBL experience.

\section{Conclusion}

The COVID-19 pandemic and lockdowns have caused schools to shift their teaching and learning online. In such a situation, technology plays a core supportive role in teaching students and their learning. The considerations to design online learning experiences to engage students meaningfully are more complex than face-to-face classroom contexts. This paper attempts to gather Singapore teachers' considerations in designing mathematics, online HBL lessons and teachers' perspectives of students' engagement during the COVID-19 pandemic lockdown in 2020.

Findings share nuanced considerations describing teachers' implementations of HBL and the importance of engaging students in an online learning context. Findings also highlight how engaged students are in an online learning context and how teachers could design online lessons to capture the attention of their students better. Although this study only looks into the perspectives of a group of mathematics teachers, findings may also apply to other subject areas.

While this study is an exploratory, qualitative study that elicits insights from a small number of mathematics teachers, findings provide evidence-informed understandings by unpacking the considerations teachers take to design lessons and engage students meaningfully in an online HBL environment. Future studies can continue to inform this area of work by involving more teachers from different subjects, grade levels, schools, and geographical contexts. The inclusion of students and parents would likely provide further insights in this field of study as well. 
Acknowledgements The authors would like to thank the participating schools and teachers for the time taken for the interviews.

Funding This study was not funded.

Data Availability The datasets generated during and/or analysed during the current study are available from the corresponding author on reasonable request.

\section{Declarations}

Conflict of interest The authors declare that we have no conflict of interest.

Ethical Approval All procedures performed in this study involving human participants were in accordance with the ethical standards of the institutional research committee. Nanyang Technological University, Institutional Review Board-IRB-2020-06-090.

\section{Appendix}

\section{Interview Questions}

1. How did you conduct your online, home-based learning during the recent school closure? Can you describe in detail how these lessons (e.g., a series of lessons) were conducted?

2. How engaged do you think were your students? How did you gauge your students' engagement levels?

3. Where or how did you get your ideas on how to conduct your lessons?

4. Were all your lessons online?

5. Were your students motivated to learn?

6. Were students engaged behaviourally, cognitively and emotionally, in your opinion?

7. Reflecting on how you were conducting your lessons during the circuit breaker period, how would you rate your lessons? Were they good, successful? If yes, why do you say so? If not, can you also reflect on them.

8. Did you experience any technical issues or complaints? You think the current technological infrastructure is adequate? What improvements can be made?

9. How do think students learning was affected by shifting it into the online environment? If so, how? If not, why?

10. Are there any other digital platforms like google classroom or zoom used other than SLS?

11. What were the difficulties you faced during this home-based learning and how you overcame them?

12. What do you think are the advantages and disadvantages of home-based learning for the teachers and students? a. What do you think are factors that hindered your teaching and student's learning?

b. How effective do you think is your teaching and students' learning in HBL?

13. How do you think home-based learning can be improved?

14. What kind of support do you think is needed to enhance home-based learning and increase the students' engagement in HBL?

\section{References}

Archambault, L., \& Larson, J. (2015). Pioneering the digital age of instruction: Learning from and about K-12 online teachers. Journal of Online Learning Research, 1(1), 49-83.

Baker, C. (2010). The impact of instructor immediacy and presence for online student affective learning, cognition, and motivation. Journal of Educators Online, 7(1), 1-30.

Bangert-Drowns, R. L., \& Pyke, C. (2002). Teacher ratings of student engagement with educational software: An exploratory study. Educational Technology Research and Development, 50(2), 23-37.

Barbour, M. K. (2013). The landscape of K-12 online learning: Examining what is known. Handbook of Distance Education, 3, 574-593.

Bond, M., \& Bedenlier, S. (2019). Facilitating student engagement through educational technology: Towards a conceptual framework. Journal of Interactive Media in Education. https://doi.org/10.5334/jime.528.

Borko, H. (2004). Professional development and teacher learning: Mapping the terrain. Educational Researcher, 33(8), 3-15.

Borup, J., West, R. E., Graham, C. R., \& Davies, R. S. (2014). The adolescent community of engagement framework: A lens for research on K-12 online learning. Journal of Technology and Teacher Education, 22(1), 107-129.

Burnham, B. R., \& Walden, B. (1997). Interactions in distance education: A report from the other side. Paper presented at the Annual Adult Education Research Conference Proceedings.

Chai, C. S., Koh, J. H. L., \& Tsai, C.-C. (2010). Facilitating preservice teachers' development of technological, pedagogical, and content knowledge (TPACK). Journal of Educational Technology \& Society, 13(4), 63-73.

Chai, C. S., Hwee Ling Koh, J., \& Teo, Y. H. (2019). Enhancing and modeling teachers' design beliefs and efficacy of technological pedagogical content knowledge for 21 st century quality learning. Journal of Educational Computing Research, 57(2), 360-384.

Curtis, H., \& Werth, L. (2015). Fostering student success and engagement in a K-12 online school. Journal of Online Learning Research, 1(2), 163-190.

Davie, S. (June 28, 2020). Home-based learning set to be regular part of schooling post Covid-19, says Education Minister Ong Ye Kung. The Straits Times. Retrieved from https://www.straitstimes.com/singapore/education/home-basedlearning-set-to-be-regular-part-of-schooling-post-covid-19-says

Dixson, M. D. (2010). Creating effective student engagement in online courses: What do students find engaging? Journal of the Scholarship of Teaching and Learning, 10, 1-13. 
Dixson, M. D. (2015). Measuring student engagement in the online course: The Online Student Engagement scale (OSE). Online Learning, 19(4), n4.

Everett, D. R. (2015). Adding value: Online student engagement. Information Systems Education Journal, 13(6), 68.

Farmer, T., \& West, R. (2019). Exploring the concerns of online K-12 teachers. Journal of Online Learning Research, 5(1), 97-118.

Fredricks, J. A., Blumenfeld, P. C., \& Paris, A. H. (2004). School engagement: Potential of the concept, state of the evidence. Review of Educational Research, 74(1), 59-109.

Fredricks, J. A., McColskey, W., Meli, J., Mordica, J., Montrosse, B., \& Mooney, K. (2011). Measuring student engagement in upper elementary through high school: A description of 21 instruments. Issues \& Answers. REL 2011-No. 098. Regional Educational Laboratory Southeast.

Gray, J. A., \& DiLoreto, M. (2016). The effects of student engagement, student satisfaction, and perceived learning in online learning environments. International Journal of Educational Leadership Preparation, 11(1), n1.

Hairon, S. (2020). Back to the future: Professional learning communities in Singapore. Asia Pacific Journal of Education, 40(4), 501-515.

Hawkins, A., \& Barbour, M. K. (2010). US virtual school trial period and course completion policy study. The American Journal of Distance Education, 24(1), 5-20.

Henrie, C. R., Halverson, L. R., \& Graham, C. R. (2015). Measuring student engagement in technology-mediated learning: A review. Computers \& Education, 90, 36-53.

Herrington, J., Oliver, R., \& Reeves, T. C. (2003). Patterns of engagement in authentic online learning environments. Australasian Journal of Educational Technology, 19(1), 59-71.

Hew, K. F., \& Brush, T. (2007). Integrating technology into K-12 teaching and learning: Current knowledge gaps and recommendations for future research. Educational Technology Research and Development, 55(3), 223-252.

Koehler, M., \& Mishra, P. (2009). What is technological pedagogical content knowledge (TPACK)? Contemporary Issues in Technology and Teacher Education, 9(1), 60-70.

Koh, T. S., \& Lee, S. C. (2008). Digital skills and education: Singapore's ICT master planning for the school sector. In S. K. Lee, C. B. Goh, B. Fredriksen, \& J. P. Tan (Eds.), Toward a better future-Education and training for economic development in Singapore since 1965 (pp. 167-190). The World Bank.

Kuh, G. D. (2003). What we're learning about student engagement from NSSE: Benchmarks for effective educational practices. Change: The Magazine of Higher Learning, 35(2), 24-32.

Kuh, G. D. (2009). The national survey of student engagement: Conceptual and empirical foundations. New Directions for Institutional Research, 2009(141), 5-20.

Kurohi, R. (April 14, 2020). Singapore schools to shift to full homebased learning from April 8 to May 4 amid Covid-19 pandemic.
The Straits Times. Retrieved from https://www.straitstimes.com/ singapore/education/schools-to-shift-to-full-home-based-learningfrom-april-8

Martin, F., \& Bolliger, D. U. (2018). Engagement matters: Student perceptions on the importance of engagement strategies in the online learning environment. Online Learning, 22(1), 205-222.

Martin, F., Parker, M. A., \& Deale, D. F. (2012). Examining interactivity in synchronous virtual classrooms. International Review of Research in Open and Distributed Learning, 13(3), 227-261.

Moore, M. G. (1989). Editorial: Three types of interaction. American Journal of Distance Education, 3(2), 1-7. https://doi.org/10.1080/08923648909526659.

Mourshed, M., Chijioke, C., \& Barber, M. (2010). How the world's most improved school systems keep getting better. McKinsey.

Northey, G., Bucic, T., Chylinski, M., \& Govind, R. (2015). Increasing student engagement using asynchronous learning. Journal of Marketing Education, 37(3), 171-180.

Patrick, S., \& Powell, A. (2009). A summary of research on the effectiveness of K-12 online learning. International Association for $K-12$ Online Learning. Retrieved from https://files.eric.ed.gov/fulltext/ED509626.pdf.

Rice, K. L. (2006). A comprehensive look at distance education in the $\mathrm{K}-12$ context. Journal of Research on Technology in Education, 38(4), 425-448.

Robinson, C. C., \& Hullinger, H. (2008). New benchmarks in higher education: Student engagement in online learning. Journal of Education for Business, 84(2), 101-109.

Sin, Y. (Jun 18, 2020). Each secondary student to get learning device by next year. The Straits Times. Retrieved from https://www.straitstimes.com/politics/each-secondary-studentto-get-learning-device-by-next-year

Smith, S. J., Burdette, P. J., Cheatham, G. A., \& Harvey, S. P. (2016). Parental role and support for online learning of students with disabilities: A paradigm shift. Journal of Special Education Leadership, 29(2), 101-112.

Tay, L. Y., Nair, S. S., \& Lim, C. P. (2017). A regression analysis of elementary students' ICT usage vis-à-vis access to technology in Singapore. Educational Media International, 54(1), 34-47.

Turgut, Y. E., \& Aslan, A. (2021). Factors affecting ICT integration in TURKISH education: A systematic review. Education and Information Technologies. https://doi.org/10.1007/s10639-02110441-2.

Weiner, C. (2003). Key ingredients to online learning: Adolescent students study in cyberspace-The nature of the study. International Journal on E-learning, 2(3), 44-50.

Publisher's Note Springer Nature remains neutral with regard to jurisdictional claims in published maps and institutional affiliations. 